\title{
Avaliação da força muscular isocinética e suas variáveis em mulheres praticantes do
}

\section{ballet pilates}

\author{
Evaluation of isokinetic muscle strength and its variables in women practicing ballet pilates \\ Evaluación de la fuerza muscular isokinética y sus variables en mujeres que practican ballet pilates
}

Recebido: 13/10/2021 | Revisado: 20/10/2021 | Aceito: 20/01/2022 | Publicado: 22/01/2022

\author{
Italo Tavares Felix \\ ORCID: https://orcid.org/0000-0001-6209-6712 \\ Universidade Tiradentes, Brasil \\ E-mail: italo18tavares@hotmail.com \\ Maria de Lourdes Santana Matos \\ ORCID: https://orcid.org/0000-0002-2121-1558 \\ Universidade Tiradentes, Brasil \\ E-mail: malumattos.santana@hotmail.com \\ Davi Santana Sousa \\ ORCID: https://orcid.org/0000-0001-7103-4441 \\ Universidade Tiradentes, Brasil \\ Universidad Popular Autónoma del Estado de Puebla, México \\ E-mail: davi.santana.sousa@hotmail.com \\ Aida Carla Santana de Melo Costa \\ ORCID: https://orcid.org/0000-0002-4192-7887 \\ Universidade Tiradentes, Brasil \\ E-mail: aida-fisio@hotmail.com
}

\begin{abstract}
Resumo
Ballet Pilates é uma modalidade inovadora que une princípios do Pilates com movimentos do Ballet Clássico, que melhora respiração, aumento da força muscular e flexibilidade. Ademais, a avaliação isocinética detecta desequilíbrios musculares. Esta pesquisa justifica-se pela escassez de publicações acerca desta modalidade de exercício, necessitando, conhecimento aperfeiçoado dos benefícios desta prática. Objetivou-se quantificar ganho de força concêntrica e excêntrica, potência e resistência muscular em praticantes de Ballet Pilates, além de identificar e quantificar os seus desequilíbrios musculares. Trata-se de um estudo piloto, de intervenção, quantitativo, comparando intraindividualmente, com amostra composta por nove participantes, praticantes durante três meses, avaliadas inicialmente e ao final com dinamômetro isocinético. Ao correlacionar desequilíbrio muscular e força concêntrica houve desequilíbrio significativo, enquanto na reavaliação, não presenciou significância estatística. Notou-se ganho de força concêntrica e aumento da resistência muscular, provando assim que o Ballet Pilates promove equilíbrio muscular e a prática trabalha força e resistência muscular.
\end{abstract}

Palavras-chave: Força muscular; Movimento; Mulher.

\begin{abstract}
Ballet Pilates is an innovative modality that combines Pilates principles with Classic Ballet movements, which improves breathing, increases muscle strength and flexibility. Furthermore, isokinetic assessment detects muscle imbalances. This research is justified by the scarcity of publications about this type of exercise, requiring improved knowledge of the benefits of this practice. The objective was to quantify concentric and eccentric strength gain, muscle power and endurance in Ballet Pilates practitioners, in addition to identifying and quantifying their muscle imbalances. This is a pilot, intervention, quantitative study, comparing intra-individually, with a sample of nine participants, practitioners for three months, initially evaluated and at the end with an isokinetic dynamometer. This is a pilot, intervention, quantitative study, comparing intra-individually, with a sample of nine participants, practitioners for three months, initially evaluated and at the end with an isokinetic dynamometer. When correlating muscle imbalance and concentric strength, there was a significant imbalance, while in the reassessment, there was no statistical significance. It was noticed a gain in concentric strength and an increase in muscular endurance, thus proving that Ballet Pilates promotes muscular balance and the practice works strength and muscular endurance.
\end{abstract}

Keywords: Muscle strength; Movement; Women.

\section{Resumen}

Ballet Pilates es una modalidad innovadora que combina los principios de Pilates con movimientos de Ballet Clásico, que mejora la respiración, aumenta la fuerza muscular y la flexibilidad. Además, la evaluación isocinética detecta desequilibrios musculares. Esta investigación se justifica por la escasez de publicaciones sobre este tipo de ejercicio, 
lo que requiere un mejor conocimiento de los beneficios de esta práctica. El objetivo fue cuantificar la ganancia de fuerza concéntrica y excéntrica, la potencia muscular y la resistencia en practicantes de Ballet Pilates, además de identificar y cuantificar sus desequilibrios musculares. Se trata de un estudio piloto, de intervención, cuantitativo, comparativo intraindividual, con una muestra de nueve participantes, practicantes durante tres meses, evaluados inicialmente y al final con dinamómetro isocinético. Al correlacionar el desequilibrio muscular y la fuerza concéntrica, hubo un desequilibrio significativo, mientras que en la reevaluación, no hubo significación estadística. Se notó una ganancia en la fuerza concéntrica y un aumento en la resistencia muscular, lo que demuestra que el Ballet Pilates promueve el equilibrio muscular y la práctica trabaja la fuerza y la resistencia muscular.

Palabras clave: Fuerza muscular; Movimiento; Mujeres.

\section{Introdução}

A atividade física é identificada como qualquer movimento corporal produzido pelo sistema musculoesquelético que resulta em gasto energético, podendo ser investigada sob as óticas do lazer, isto é, aquela realizada no tempo livre. Os exercícios físicos regulares podem prevenir obesidade, diabetes, dislipidemias e doenças cardíacas. Cabe lembrar que a prática dessas atividades diminui com o avanço da idade, o que pode associar-se à diminuição da capacidade física (Neto et al., 2012; Polissen, 2014).

O Ballet Pilates foi desenvolvido na Inglaterra, sendo uma modalidade que mescla os princípios do Pilates, que enfatizam o controle da mente sobre o corpo, a suavidade, precisão e harmonia; com os princípios do Ballet Barré Workout, que visa uma postura ereta, com movimentos circulares dos membros superiores, verticalidade corporal, disciplina, leveza, harmonia e simetria. Em pouco tempo, é possível perceber resultados, como redução do peso, fortalecimento dos músculos e melhora da postura, sendo todo o corpo trabalhado durante a aula (Bernadi, 2017).

$\mathrm{Na}$ barra, os exercícios específicos do ballet ajudam a dar ênfase aos membros inferiores e, no solo, a ênfase maior é no abdômen e nos membros superiores. Entretanto, devido à grande gama de exercícios, também é possível trabalhar membros superiores na barra e inferiores no centro da sala através dos agachamentos (Gosling, 2017).

O treino é rigoroso e complexo e as dezesseis repetições em cada exercício são os grandes segredos de sucesso de uma atividade bem executada, focada em cada grupo muscular. Tais movimentos melhoram a mobilidade articular e desenvolvem a força muscular, além de contribuir para o condicionamento cardiovascular, os quais são enfatizados durante a aula. Durante o treino, é trabalhada a consciência corporal, além de equilíbrio e força. Além de melhorar a postura, ainda favorece a prevenção de lesões (Scinocca, 2016; Barcelos et al., 2018).

Por otimizar a condição aeróbica, a força e a flexibilidade, as aulas podem ser coadjuvantes para treinos de atletas, corredores amadores, adeptos da dança e até mesmo para praticantes de musculação, assim como para indivíduos previamente sedentários (Scinocca, 2016).

A força muscular é uma variável importante de ser avaliada para identificar indivíduos que possam estar em um grupo de risco para o desenvolvimento de lesões musculoesqueléticas. Neste sentido, a avaliação isocinética tem sido amplamente utilizada nas últimas décadas como método para quantificar a força e detectar possíveis desequilíbrios musculares, uma vez que o dinamômetro isocinético fornece dados fidedignos e reprodutíveis (Zabka, 2011; Zapparoli \& Riberto, 2017; Barcelos et al., 2018).

Por sua vez, a avaliação isocinética torna-se cada vez mais necessária na prática esportiva, uma vez que permite identificar e quantificar o desempenho e o equilíbrio muscular de atletas. Tal método apresenta grande confiabilidade, permitindo testar diferentes tipos de força: isométrica, isocinética e torque em diferentes graus de amplitude de movimento (Zabka, 2011; Lopes, 2017).

Por se tratar de uma modalidade de alta intensidade e baixo impacto, o Ballet Pilates tem a capacidade de adaptar seus exercícios para qualquer tipo de indivíduo, desenvolvendo ganho de força muscular concêntrica, excêntrica, potência e resistência em flexores e extensores de joelho, além de se tratar de uma atividade recém desenvolvida, o que reflete uma 
escassez de publicações na literatura nacional e internacional, trazendo a importância de pesquisas com essa temática, a fim de se conhecer melhor os benefícios da prática.

Diante desse cenário, o presente estudo teve como objetivo geral analisar o ganho de força, potência e resistência isocinética em mulheres praticantes do Ballet Pilates. Os objetivos específicos foram: 1). Identificar e quantificar os desequilíbrios musculares apresentados pelas alunas praticantes da modalidade; 2). Verificar o ganho de resistência muscular com a prática da atividade; 3). Comparar a força muscular concêntrica e excêntrica antes e após a execução do Ballet Pilates.

\section{Metodologia}

\subsection{Delineamento Da Pesquisa}

Trata-se de um estudo piloto, de intervenção, de comparação intraindividual e natureza quantitativa, realizado mediante autorização e assinatura do Termo de Consentimento Livre e Esclarecido (TCLE) pelas voluntárias avaliadas. Optouse por esta modalidade por proporcionar a compreensão sobre os efeitos da força muscular em mulheres praticantes de Ballet Pilates.

\subsection{Aspectos Éticos}

O projeto foi encaminhado ao Comitê de Ética em Pesquisa (CEP) da Universidade Tiradentes (UNIT) via Plataforma Brasil para solicitação de liberação. Os termos da Resolução 466/12, de 12 de dezembro de 2012, do Conselho Nacional de Saúde do Ministério de Saúde foram respeitados, assim como as normas e resoluções advindas do Grupo Mercado Comum (GMC) $\mathrm{N}^{\circ}$ 129/96, obedecendo à Lei 6.360 (23 de setembro de 1976), em especial o Art. 76, regulamentado pelo Decreto $\mathrm{N}^{\circ}$ 79.094 (05 de janeiro de 1977).

\subsection{Local Da Pesquisa E Caracterização}

A pesquisa foi realizada na Zona Alvo Centro de Saúde e Performance Humana, uma vez que o local dispõe de infraestrutura e equipamentos adequados para a realização do estudo, além de ser pioneiro no Estado de Sergipe no que diz respeito à avaliação isocinética.

\subsection{Casuística}

A amostra foi por conveniência, sendo avaliadas individualmente nove $(n=09)$ mulheres praticantes de Ballet Pilates, selecionadas a partir de critérios de inclusão estabelecidos, a saber: faixa etária de 20 a 50 anos e prática da modalidade em uma frequência de três vezes semanais. Foram excluídas do estudo mulheres que praticassem qualquer outra atividade física simultaneamente ou que apresentassem alguma patologia que interferisse na força muscular, além de gestantes.

O recrutamento foi feito na Zona Alvo Centro de Saúde e Performance Humana, uma vez que o estúdio de Ballet Pilates tem sede neste local. A coleta de dados foi realizada em um período de três meses, sendo as alunas avaliadas antes de iniciar a atividade e após três meses de execução.

\subsection{Instrumentos E Procedimentos Para Coleta De Dados}

Neste estudo, foi utilizado um protocolo para avaliar força concêntrica, potência, resistência e força excêntrica dos músculos extensores e flexores de joelho, utilizando um dinamômetro isocinético (Cybex Norm 770). Para a avaliação, as voluntárias foram posicionadas em sedestação, com ângulo do encosto a $90^{\circ}$ de flexão do quadril e flexão de joelho a $90^{\circ}$, utilizando cintas estabilizadoras no tronco e membro avaliado, a fim de evitar movimentos compensatórios.

O equipamento foi calibrado com amplitude de movimento a partir de uma flexão máxima até uma extensão máxima 
do joelho. $\mathrm{O}$ membro de teste foi pesado a $45^{\circ}$ de extensão pelo equipamento para evitar o viés causado pela gravidade. Os membros superiores foram posicionados lateralmente segurando as alças da cadeira, com cintos ajustados em todos os indivíduos previamente posicionados de maneira correta da seguinte forma: dois cintos em região de tronco de maneira transversal em cada lado do corpo; um cinto na horizontal em região de quadril; outro cinto na perna contralateral à qual foi realizada a avaliação; e o cinto que acopla o aparelho à perna da participante.

O dinamômetro foi posicionado na lateral com um ângulo fixo de $40^{\circ}$. Antes do teste, os participantes receberam instruções detalhadas para o procedimento que iriam realizar. Em seguida, foi feita a avaliação bilateral e, em cada lado, foram realizadas duas séries de cinco repetições a $60 \%$ para força concêntrica e excêntrica, cinco repetições a $180 \%$ para avaliar potência muscular e vinte repetições a $240 \%$ s para avaliar a resistência da musculatura do joelho, sendo a inicial apenas uma familiarização para conhecimento do funcionamento do aparelho e a posterior foi a coleta do teste real.

A primeira dessas duas séries consistiu em repetições submáximas, e a segunda foi em força máxima. Entre a familiarização e a série de teste real, houve um intervalo de descanso de 1 minuto. Vale ressaltar que a coleta tanto inicial quanto final dessas variáveis foi feita sempre pelo mesmo pesquisador, assim como foi obrigatório o uso da cinta estabilizadora em todas as mensurações realizadas de força muscular.

\subsection{Análise Estatística}

Inicialmente, os dados coletados foram transportados para uma planilha de dados no programa Excel for Windows 10, em que foi realizada a estatística descritiva, com as medidas de posição (média) e de dispersão (desvio padrão). Posteriormente, foram feitas análises no programa GraphPad Prisma 6.

Todas as variáveis foram testadas quanto à normalidade através do teste de Shapiro-Wilk. Na comparação intragrupo, os dados que seguiram distribuição normal foram analisados por meio dos testes t pareado ou Mann-Whitney, se foram paramétricos ou não paramétricos. Para correlação entre as variáveis, foi utilizado o teste de correlação de Pearson ou Spearman, para dados paramétricos ou não-paramétricos, respectivamente. O nível de significância foi fixado em p<0,05 e os dados foram representados por média \pm desvio padrão.

\section{Resultados}

Na Tabela 1, notou-se um aumento discreto nas variáveis resistência e força excêntrica em quadríceps direito e esquerdo, embora não tenha sido observado significância estatística, com $\mathrm{p}=0,244$ e $\mathrm{p}=0,494$, respectivamente, para o reequilíbrio muscular. Em relação à força muscular concêntrica, embora tenha havido redução desta variável de maneira bilateral, foi constatada a diminuição dos desequilíbrios musculares, com p=0,023. 
Tabela 1. Avaliação do quadríceps de praticantes do Ballet Pilates. Dados apresentados em média \pm desvio padrão. Teste t não-pareado e Teste de Mann-Whitney. $* \mathrm{p}<0,05$.

\begin{tabular}{llll}
\hline Avaliação do Quadríceps & \multicolumn{1}{c}{ Avaliação } & Reavaliação & p \\
\hline Força concêntrica direita (Nm) & $113,11 \pm 28,04$ & $109,67 \pm 16,25$ & 0,754 \\
Força concêntrica esquerda (Nm) & $119,89 \pm 24,9$ & $114,89 \pm 16,94$ & 0,625 \\
Desequilíbrio de força concêntrica (\%) & $14,67 \pm 6,2$ & $8 \pm 4,95$ & $0,023^{*}$ \\
Potência direita (Nm) & $75,67 \pm 18,04$ & $73,22 \pm 16,44$ & 0,814 \\
Potência esquerda (Nm) & $77,56 \pm 12,56$ & $80,33 \pm 14,4$ & 0,669 \\
Desequilíbrio de potência (\%) & $9,67 \pm 6,36$ & $10,78 \pm 9,05$ & 0,767 \\
Resistência direita (Nm) & $54,67 \pm 17,06$ & $59,56 \pm 13,74$ & 0,421 \\
Resistência esquerda (Nm) & $56,67 \pm 10,07$ & $60 \pm 14,35$ & 0,577 \\
Desequilíbrio de resistência (\%) & $14,33 \pm 14,05$ & $7,33 \pm 6,63$ & 0,244 \\
Força excêntrica de direita (Nm) & $143,22 \pm 37,28$ & $150,78 \pm 19,16$ & 0,214 \\
Força excêntrica esquerda (Nm) & $135,33 \pm 34,29$ & $140,33 \pm 21,77$ & 0,717 \\
Desequilíbrio de força excêntrica (\%) & $14 \pm 10,51$ & $11,11 \pm 6,55$ & 0,494 \\
\hline
\end{tabular}

Fonte: Dados da pesquisa.

$\mathrm{Na}$ Tabela 2, foi perceptível que houve uma proporcionalidade entre os isquiotibiais direito e esquerdo, considerando os ganhos em todas as variáveis analisadas. Assim, pode-se observar que foi adquirida uma simetria muscular no que diz respeito à força concêntrica, com significância estatística $(\mathrm{p}=0,031)$.

Tabela 2. Avaliação dos isquiotibiais de praticantes do Ballet Pilates. Dados apresentados em média \pm desvio padrão. Teste $t$ não-pareado e Teste de Mann-Whitney. *p<0,05.

\begin{tabular}{llll}
\hline Avaliação dos Isquiotibiais & \multicolumn{1}{c}{ Avaliação } & Reavaliação & p \\
\hline Força concêntrica direita (Nm) & $57,67 \pm 13,29$ & $60,22 \pm 11,98$ & 0,449 \\
Força concêntrica esquerda (Nm) & $69,67 \pm 18,37$ & $65,89 \pm 17,48$ & 0,661 \\
Desequilíbrio de força concêntrica (\%) & $18,89 \pm 9,65$ & $9,22 \pm 7,5$ & $0,031^{*}$ \\
Potência direita (Nm) & $45,22 \pm 13,98$ & $47,33 \pm 8,96$ & 0,182 \\
Potência esquerda (Nm) & $48,22 \pm 8,79$ & $48,44 \pm 10,53$ & 0,962 \\
Desequilíbrio de potência (\%) & $15,33 \pm 6,75$ & $9,67 \pm 6,2$ & 0,082 \\
Resistência direita (Nm) & $37 \pm 6,38$ & $39,11 \pm 7,34$ & 0,524 \\
Resistência esquerda (Nm) & $39,11 \pm 7,72$ & $41 \pm 9,3$ & 0,645 \\
Desequilíbrio de resistência (\%) & $12 \pm 11,37$ & $7,44 \pm 5,77$ & 0,300 \\
Força excêntrica direita (Nm) & $81,56 \pm 22,77$ & $79,33 \pm 11,72$ & 0,798 \\
Força excêntrica esquerda (Nm) & $87,33 \pm 26,73$ & $80,67 \pm 18,62$ & 0,548 \\
Desequilíbrio de força excêntrica (\%) & $10,33 \pm 7,95$ & $9,11 \pm 6,58$ & 0,727
\end{tabular}

Fonte: Dados da pesquisa.

Na Figura 1, ao serem avaliados e reavaliados os grupos musculares Quadríceps e Isquiotibiais após a prática de 3 meses do Ballet Pilates, observou-se que houve um ganho de resistência muscular bilateralmente. 
Figura 1. Resistência muscular das praticantes de Ballet Pilates. Dados apresentados em média \pm desvio padrão.

\section{Resistência muscular}

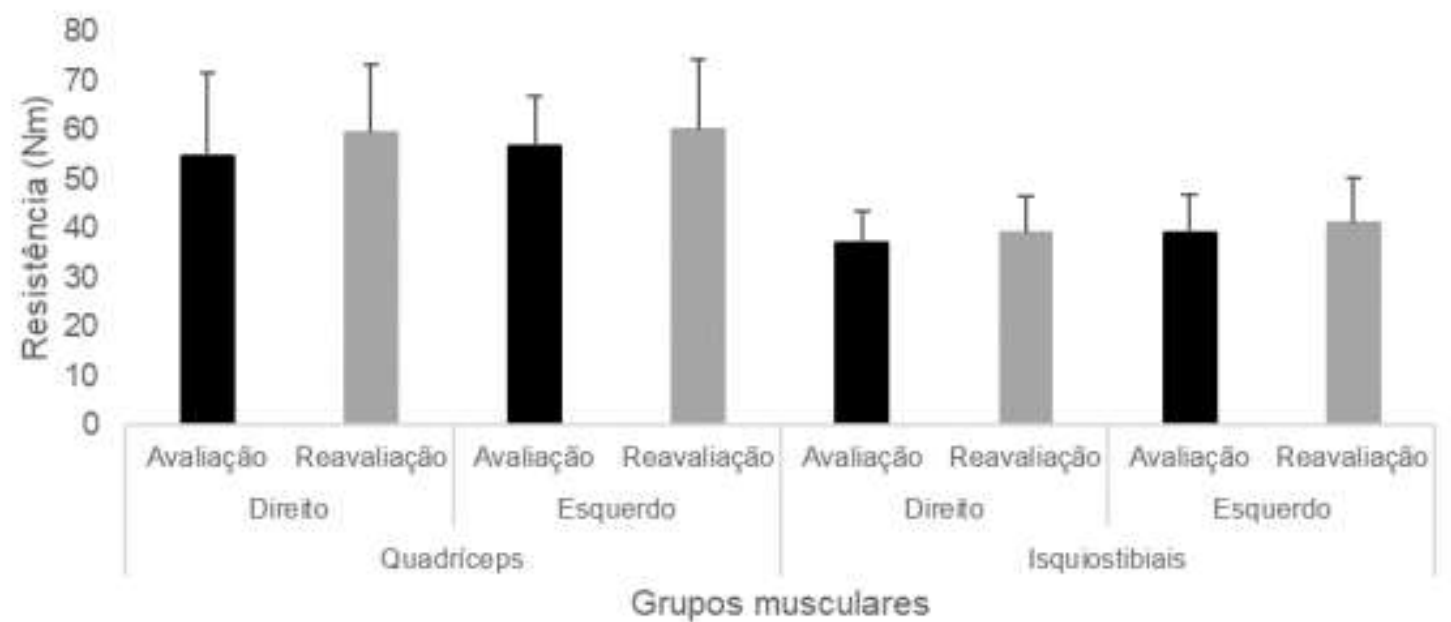

Fonte: Dados da pesquisa.

Na Figura 2, ao se tratar da avaliação referente ao desequilíbrio muscular, houve uma diminuição dos déficits das variáveis, sendo o reequilíbrio da força concêntrica com resultados mais significativos, com $p=0,023$ para quadríceps e $\mathrm{p}=0,031$ para isquiotibiais.

Figura 2. Desequilíbrios musculares das praticantes de Ballet Pilates. Dados apresentados em média \pm desvio padrão. Teste de Mann-Whitney. *p<0,05.

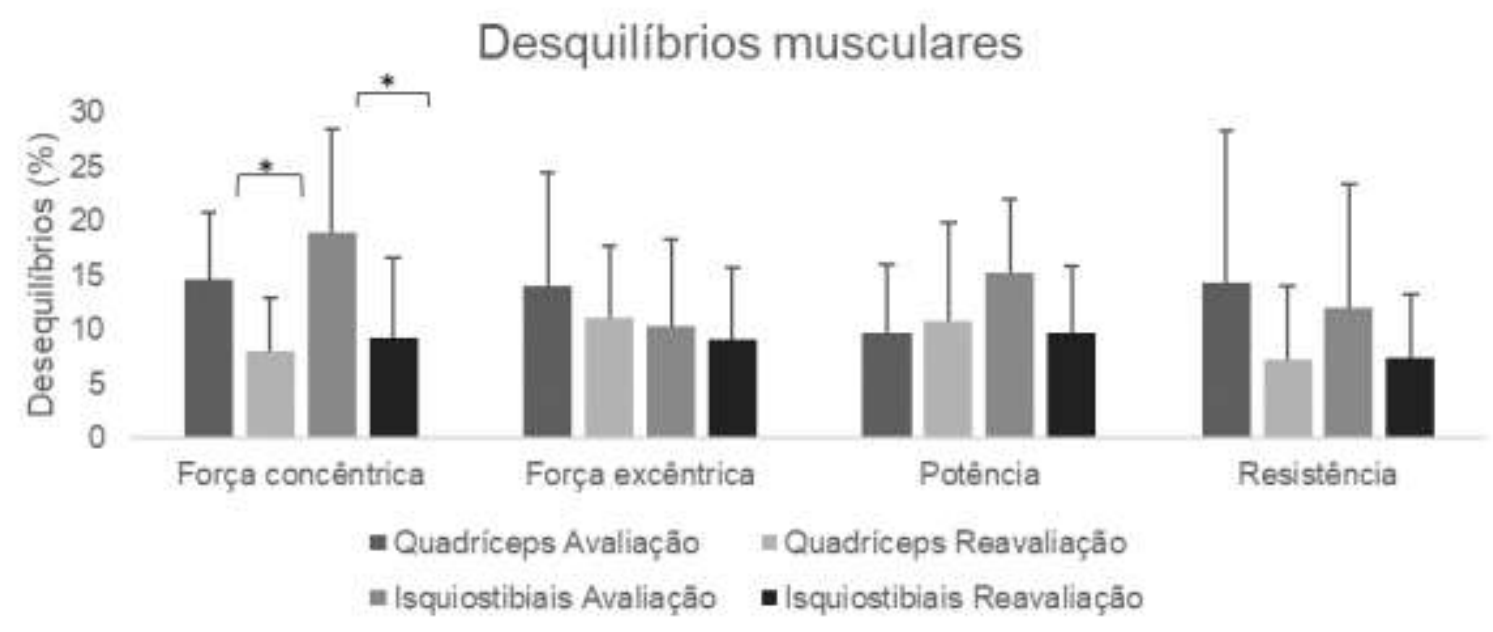

Fonte: Dados da pesquisa.

Nas correlações de desequilíbrio muscular e força concêntrica de quadríceps direito, notou-se que na avaliação houve um desequilíbrio muscular significativo $(\mathrm{p}=0,015)$, enquanto na reavaliação não foi notada significância estatística $(\mathrm{p}=0,401)$ em relação ao desequilíbrio, provando assim que a prática do Ballet Pilates causou um equilíbrio muscular (Figuras 3 e 4). 
Figura 3. Correlação entre a força concêntrica de quadríceps direito e o desequilíbrio de força concêntrica do quadríceps, na avaliação. Teste de correlação de Pearson. *p<0,05.

\section{Quadríceps direito- Avaliação}

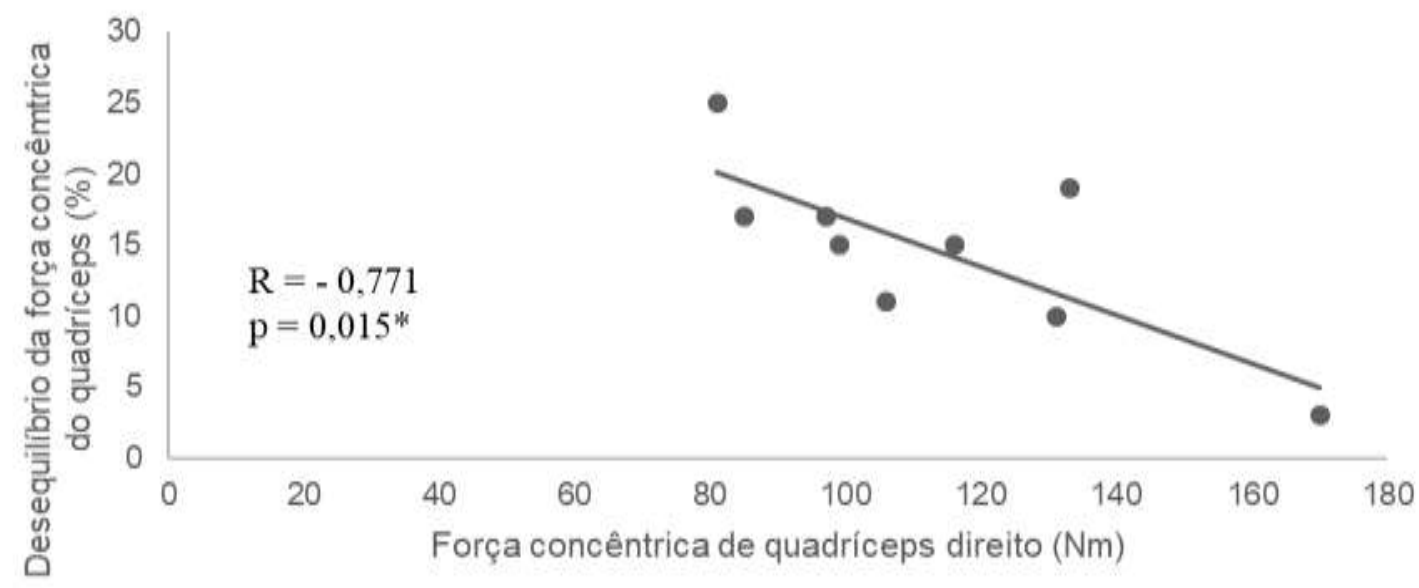

Fonte: Dados da pesquisa.

Figura 4. Correlação entre a força concêntrica de quadríceps direito e o desequilíbrio de força concêntrica do quadríceps, na reavaliação. Teste de correlação de Pearson. *p<0,05.

\section{Quadríceps direito - Reavaliação}

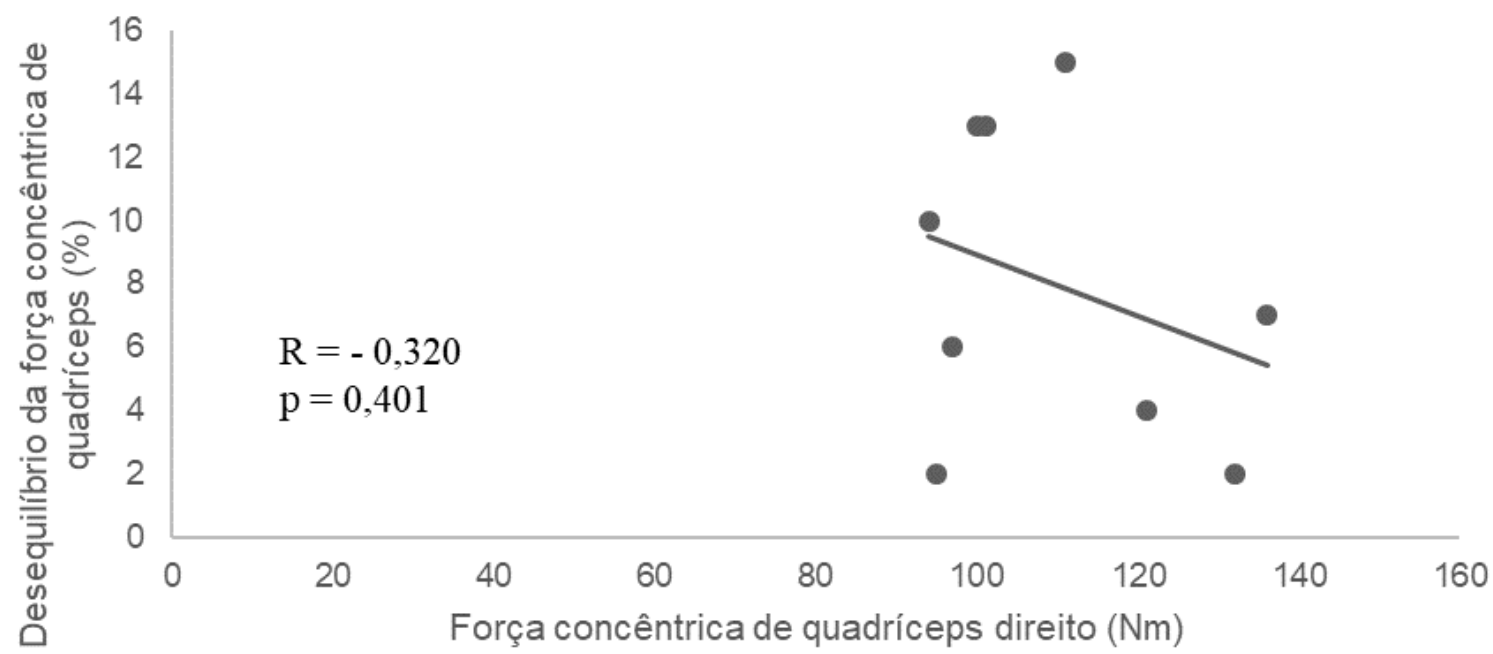

Fonte: Dados da pesquisa.

Nas correlações de desequilíbrio muscular e força concêntrica de quadríceps esquerdo, notou-se que na avaliação houve um desequilíbrio muscular significativo $(\mathrm{p}=0,018)$, enquanto na reavaliação não foi notada significância estatística ( $p=0,985)$ em relação ao desequilíbrio, provando assim que a prática do Ballet Pilates causou um equilíbrio muscular (Figuras 5 e 6 ). 
Figura 5. Correlação entre a força concêntrica de quadríceps esquerdo e o desequilíbrio de força concêntrica do quadríceps na avaliação. Teste de correlação de Pearson. *p<0,05.

\section{Quadríceps esquerdo - Avaliação}

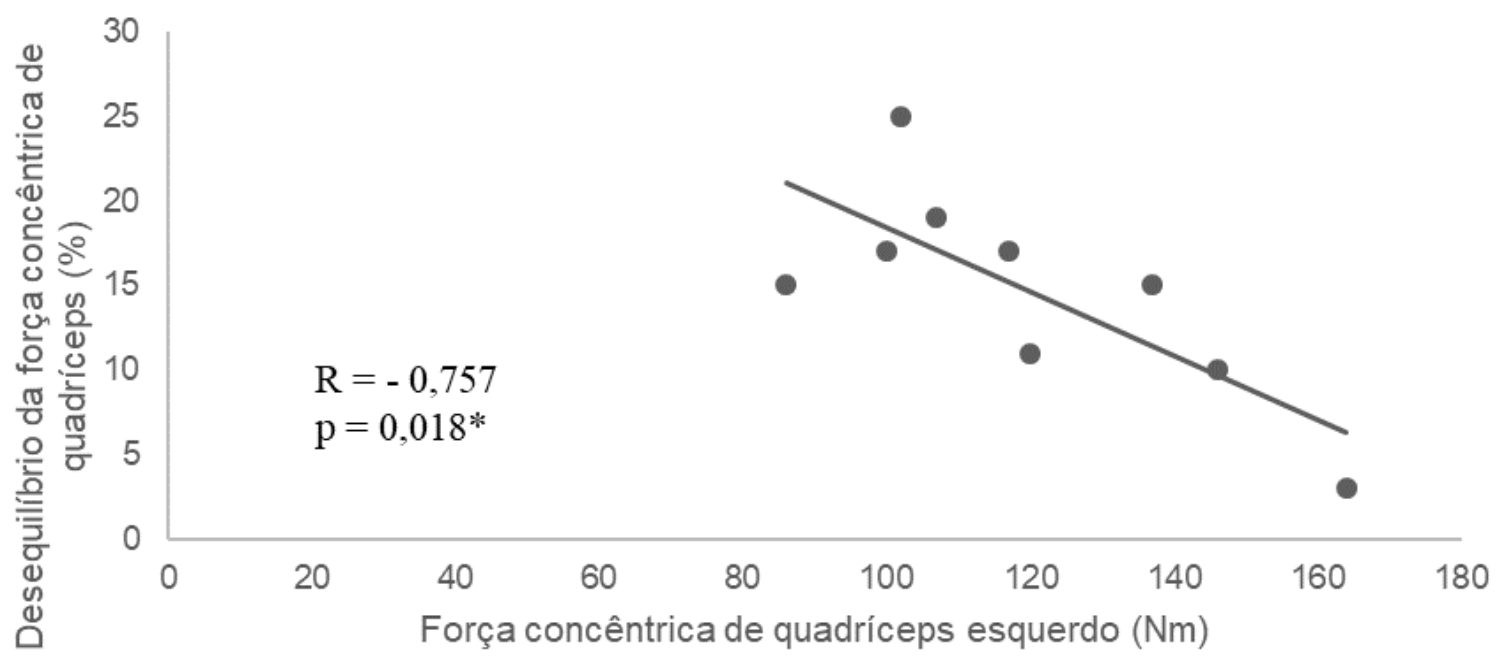

Fonte: Dados da pesquisa.

Figura 6. Correlação entre a força concêntrica de quadríceps esquerdo e o desequilíbrio de força concêntrica do quadríceps na reavaliação. Teste de correlação de Pearson. *p<0,05.

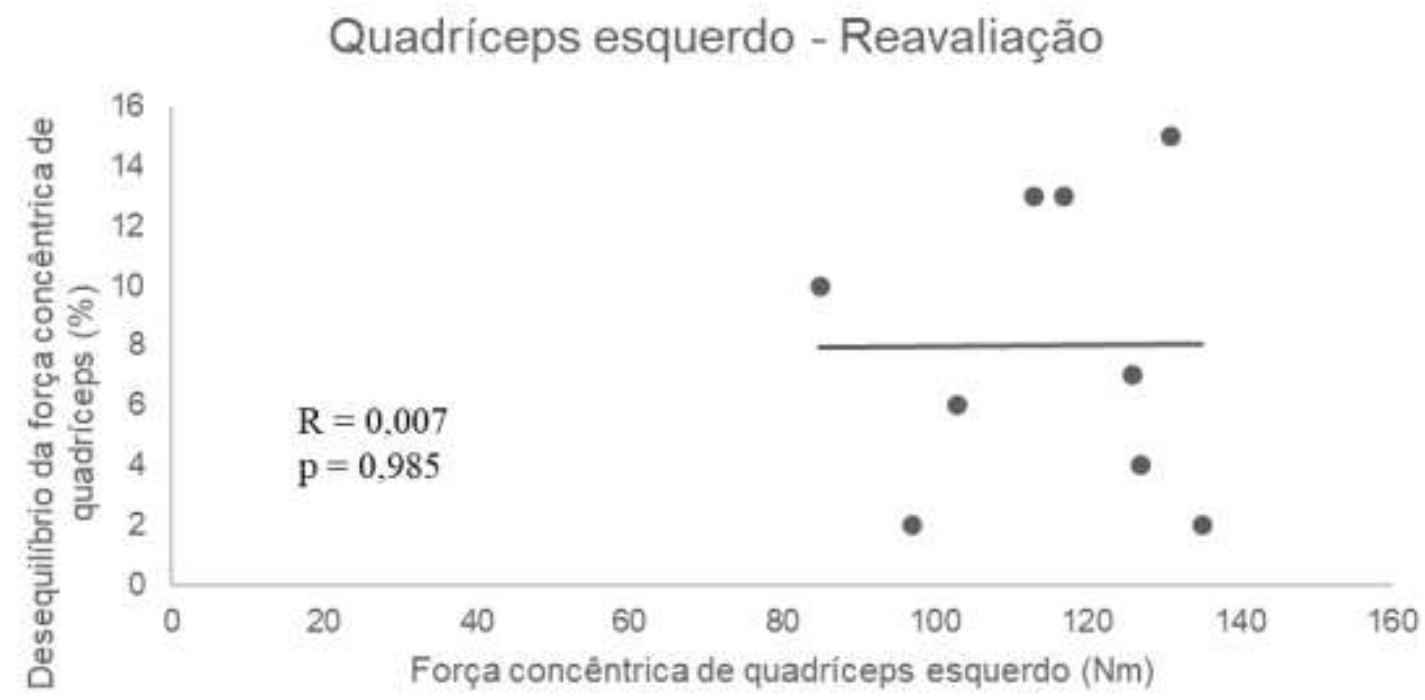

Fonte: Dados da pesquisa.

\section{Discussão}

A partir do estudo realizado, foram avaliadas variáveis como força concêntrica e excêntrica, potência e resistência, bem como os possíveis desequilíbrios dos grupos musculares flexores e extensores de joelho em mulheres praticantes do método Ballet Pilates, a fim de melhor compreensão dos benefícios atribuídos por essa modalidade, em se tratando de ser uma prática inovadora, recém desenvolvida e com escassez de publicações científicas.

Saenz et al. (2010) relatam que o dinamômetro isocinético consiste em um equipamento que fornece informações 
precisas nas avaliações relacionadas à força, potência e resistência de grupos musculares, com excelente confiabilidade testereteste, principalmente quando se utiliza o desequilíbrio muscular como variável. Neste estudo, optou-se pelo referido instrumento de avaliação, com a finalidade de quantificar os níveis de pico de torque e possíveis assimetrias musculares.

Ratificando o que Saenz et al. (2010) citaram, Bittencourt et al. (2005) afirmam que os testes isocinéticos são amplamente utilizados por estudos em populações de atletas, pois fornecem valores objetivos, confiáveis e reprodutíveis da função muscular de diversas articulações. Da mesma forma, esses testes possibilitam a avaliação de parâmetros relacionados à performance muscular, como força, trabalho, potência e desequilíbrios entre músculos agonistas e antagonistas. Portanto, essas medidas obtidas através da avaliação isocinética podem ser bastante eficientes na detecção de alterações musculoesqueléticas, orientação de medidas preventivas, implementação de programas de treinamentos específicos para cada atleta e de melhora do desempenho esportivo.

De acordo com Oliveira et al. (2015), assim como no Pilates, no Ballet Pilates é preconizado o fortalecimento muscular não apenas de eixo corporal, mas também de outras regiões, como membros superiores e inferiores. Para os membros inferiores em especial, o nível de fortalecimento muscular pode contribuir para a execução de tarefas do cotidiano ou representar ganho de desempenho em diversas modalidades esportivas. Pessoas saudáveis, atletas ou em processo de reabilitação podem utilizar-se desta forma de exercício, objetivando aumento da força muscular dos extensores e flexores do joelho.

Segundo Bartolomei et al. (2014), em pesquisas cujo objetivo seja a melhora da força muscular, tal resultado costuma ser verificado tradicionalmente com fins de reabilitação fisioterapêutica. No entanto, este controle muscular mostra-se efetivo e fundamental para ganho de performance em indivíduos saudáveis ou para melhora do desempenho esportivo e não apenas voltado para a reabilitação. Lima et al. (2011) e Mata; Espig; Santos (2012) complementam que o desenvolvimento da força depende de vários fatores, como composição das fibras musculares em determinados músculos, velocidade de execução, carga utilizada, número de séries, repetições, intervalos e frequência da atividade.

No estudo em vigor, foi observado não apenas o ganho de força muscular, mas, principalmente, o favorecimento da resistência muscular, o que pode ser justificado pelo protocolo utilizado nesta modalidade que visa a utilização de baixas cargas e elevadas repetições durante a execução da atividade.

Para Santos (2016), considerando a modalidade do Ballet Clássico, há uma busca constante dos padrões estéticos exagerados, com execução de movimentos, gerando grande força muscular e elevada amplitude de movimento articular, ratificando que esta modalidade demanda alto grau de tensão muscular, com necessidade de desenvolver as habilidades físicas, como flexibilidade, resistência, coordenação, velocidade, equilíbrio e, principalmente, força, tendo em vista a busca de uma performance adequada. Anand Prakash (2017) acrescenta que, em decorrência do estresse mecânico ocasionado pelo Ballet Clássico, nota-se uma susceptibilidade para lesões em membros inferiores, particularmente na articulação do joelho, as quais atingem com frequência essa população.

Souza (2017) realizou uma pesquisa voltada apenas para bailarinas clássicas, mas afirmou que o Ballet Pilates é importante para todos os bailarinos/dançarinos, de qualquer estilo ou vertente, pois a evolução em seu preparo físico é observada em curto período de tempo, confirmando que o Ballet Pilates representa uma atividade que pode ser praticada não somente por bailarinos ou pessoas ligadas à dança, mas também por qualquer indivíduo, por ser um método de condicionamento físico e treino funcional. Reforçando essa afirmação, Lara (2017) acrescenta que o Ballet Pilates surgiu como uma alternativa para a reabilitação de bailarinos clássicos, tendo como proposta oferecer segurança para os movimentos corporais, sem causar lesões aos praticantes, respeitando a sua individualidade e incentivando a postura corporal ideal durante a execução dos exercícios.

De acordo com Aquino et al. (2010), os desequilíbrios musculares são alterações no recrutamento de um ou mais 
músculos dentro de um determinado movimento, o que pode gerar disfunções e contribuir para o surgimento de patologias, muitas vezes, incapacitantes do ponto de vista funcional. Do mesmo modo, o desequilíbrio muscular entre sinergistas, quando comparado com os outros músculos também responsáveis pelo movimento, pode alterar a estabilidade articular, acarretando condições dolorosas. Porém, vale ressaltar que desequilíbrios musculares podem estar presentes na ausência de dor ou incapacidade funcional.

Estudos realizados por Andrade et al. (2005) afirmam que a força muscular, assim como a deficiência contralateral e o desequilíbrio entre músculos agonistas e antagonistas de determinada articulação são considerados fatores de risco para o desenvolvimento de lesões do aparelho locomotor, principalmente quando esses fatores são associados à atividade física. Na atual pesquisa, observou-se um reequilíbrio muscular látero-lateral, uma vez que a prática do Ballet Pilates enfatiza atividades unipodais que podem contribuir para o reequilíbrio muscular.

Com base no estudo de Pícoli (2011), na terceira década de vida, é atingido o pico de força máxima, observando-se um declínio de 12 a $14 \%$ por década a partir dos 50 anos, podendo chegar a $40 \%$ por década quando relacionados aos valores de potência muscular na faixa dos 70 anos. Sabe-se que o declínio da potência muscular afeta diretamente a realização de atividades de vida diária e a independência funcional. Dessa forma, com o intuito de melhorar a capacidade funcional, o treinamento de força mostra-se como um meio eficaz para a redução das alterações decorrentes do processo de envelhecimento. Neste sentido, o Ballet Pilates vem com uma proposta diferenciada, envolvendo atividades cardiovasculares, de força, resistência, coordenação, equilíbrio e flexibilidade, requisitos que asseguram ao indivíduo a independência funcional.

Segundo Lara (2017), a prática da atividade do Ballet Pilates é indicada para todas as idades a partir dos 12 anos, já que é uma atividade com acompanhamento e que permite a adequação dos exercícios para qualquer faixa etária. Na pesquisa atual, observou-se uma média de idade de 35 anos para as mulheres incluídas na abordagem. Blum (2002) afirma que foram demonstrados resultados favoráveis em promover aumento em todos os parâmetros avaliados (pico de torque, trabalho total, potência e resistência). Verificou-se que os benefícios apresentados, principalmente no que se refere a problemas posturais, teriam ocorrido devido a uma melhor relação entre flexores e extensores em todos os parâmetros avaliados, citados previamente, tendendo a haver o equilíbrio entre grupos musculares. Tais resultados ratificam os do Ballet Pilates, visto que essa modalidade é uma excelente alternativa para indivíduos que necessitem desenvolver tal equilíbrio muscular, por gerar melhor simetria muscular nas variáveis analisadas.

Em pesquisa realizada por Oliveira et al. (2015), mesmo diante de um curto período de intervenção, notou-se discreto aumento do torque isocinético nos indivíduos avaliados e, principalmente, melhora do equilíbrio muscular entre os membros inferiores, a partir da utilização de elevado número de repetições executadas durante a atividade, assim como baixa carga e impacto, embora com manutenção de alta intensidade. Silva et al. (2012) afirmaram que programas de treinamento físico de resistência muscular que tiveram como objetivo identificar o pico de torque isocinético dos extensores e flexores do joelho em mulheres, tipicamente, utilizam-se de períodos de intervenção superiores a doze semanas, a fim de identificar melhora da variável. Este resultado corrobora os dados encontrados na presente pesquisa, uma vez que foi observada discreta evolução na força muscular, possivelmente em decorrência do tempo de realização da prática cuja reavaliação foi estabelecida em três meses de atividade, podendo-se inferir que o ganho de força muscular se torna mais expressivo após esse período.

\section{Conclusão e Considerações Finais}

Com esta pesquisa, tornou-se perceptível que o Ballet Pilates, além de constituir uma alternativa para proporcionar aumento de força muscular de suas praticantes, é também uma modalidade que permite ganho de resistência. Como principal benefício, foi observado um reequilíbrio das musculaturas estabilizadoras dos membros inferiores, sendo de fundamental importância para a prevenção de lesões e aumento da performance. 
Diante do exposto, visando à importância da modalidade na promoção à saúde e prevenção de doenças, o Ballet Pilates ocasiona, consequentemente, melhora na qualidade de vida, eliminação do sedentarismo e minimização dos riscos de lesões na prática de outras atividades físicas, inclusive de atletas, já que os desequilíbrios musculares se apresentam como uma das principais causas de lesões no esporte. Por essa razão, faz-se necessária a realização de novos estudos acerca desta modalidade, com uma amostra mais representativa e em maior intervalo de tempo para as devidas reavaliações.

\section{Referências}

Anand Prakash, A. (2017). Medical attention seeking dance injuries: systematic review of case reports. The Physician and Sports Medicine, 45(1), p. 64-74.

Andrade, M. A. S., Fleury, A. M., \& Silva, A. C. (2005). Força muscular isocinética de jogadores de futebol da seleção paraolímpica brasileira de portadores de paralisia cerebral. Rev Bras Med Esporte, 11(5).

Aquino, C. F. De, Cardoso, V. A., \& Machado, N. C. (2010). Análise da relação entre dor lombar e desequilíbrio de força muscular em bailarinas. ISSN 01035150 Fisioter. Mov., Curitiba, 23(3), p. 399-408.

Barcelos, B. B., Texeira, L. P., \& Lara, S. (2018). Análise do equilíbrio postural e força muscular isocinética de joelho em atletas de futsal feminino. Fisioter Pesqui., 25(1), p. 28-34.

Bartolomei S1, Hoffman JR, Merni F, \& Stout JR. (2014). A comparison of traditional and block periodized strength training programs in trained athletes. $J$ Strength Cond Res., 28(4), p.990-7.

Bernardi, D. (2019). Ballet pilates queima 600 calorias e deixa o abdômen durinho. BOA FORMA. https://boaforma.abril.com.br/fitness/ballet-pilates-queima600-calorias-deixa-abdomen-com.

Bittencourt, N. F. N. et al. (2005). Avaliação muscular isocinética da articulação do joelho em atletas das seleções brasileiras infanto e juvenil de voleibol masculino. Rev Bras Med Esporte, 11(6).

Blum, C. L. (2002). Chiropractic and Pilates therapy for the treatment of adult scoliosis. J Manipulative Physiol Ther.,25(4).

gosling, R. (2017). Ballet Pilates, sabe tudo sobre essa modalidade? Vamos te contar um pouco sobre ela e os seus benefícios!!!. Ballet Paula Castro. Agosto. https://balletpaulacastro.com.br/2017/08/08/tudo-o-que-voce-precisa-saber-sobre ballet-pilates/. Acesso em 13/02/2019.

Lara, A. (2017). O Método Ballet Pilates. https://www.audrealara.com/restrito/balletpilates/. Acesso em 06/11/19.

Lima, K. A. et al. (2011). Efeitos Da Prática Dos Métodos Pilates E Musculação Sobre a Aptidão Física E Composição Corporal em Mulheres. Pespectiva online, ciências biológicas e da saúde.

Lopes, J. A. L. (2017). Desenvolvimento de dispositivo para avaliação de força em pacientes não cooperativos. Dissertação de Mestrado em Engenharia Biomédica, Publicação 074A/2017, Programa de Pós-Graduação em Engenharia Biomédica, Faculdade Gama, Universidade de Brasília, Brasília, DF, p.71.

Mata, C. S., Espig, C. C., \& Dos Santos, D. B. (2012). Efeitos de um treinamento de hipertrofia no ganho de força muscular e variação da composição corporal de mulheres participantes de musculação de academia. Revista Brasileira de Prescrição e Fisiologia do Exercício, 5(27).

Neto, A. M. P., Valadares, A. L. R., \& Costa-Paiva, L. (2012). Atividade física em mulheres brasileiras. Rev Bras Ginecol Obstet., 34 (10), $439-41$.

Neto, A. G., \& Preis, C. (2005). A valorização do treino muscular excentrico na fisioterapia desportiva. Fisioterapia em Movimento, 18(1), $19-26$.

Oliveira, R. G. et al. (2015). Efeitos do método pilates no torque isocinético dos extensores e flexores do joelho: estudo piloto. Rev Bras Med Esporte, 21(1), 2015 .

Pícoli, T. S., Figueiredo, L. L. De, \& Patrizz L. J. (2011). Sarcopenia e envelhecimento. Fisioter. Mov., 24(3).

Polissen, M. L. C., \& Ribeiro, L. C. (2014). Exercício físico como fator de proteção para a saúde em servidores públicos. Rev. Bras. Med. Esporte., 20(5), p.340-344.

Souza, A. A. V. (2017). A importância do Ballet Pilates para o preparo físico da bailarina clássica. Dados Internacionais de Catalogação na Publicação (CIP) Biblioteca Universitária do ICA/ETDUFPA, Belém-PA.

Saenz, A. et al. (2010). Knee isokinetic test-retest: a multicentre knee isokinetic test-retest study of a fatigue protocol. Eur J Phys Rehabil Med., 46(1).

Silva, R. F. et al. (2012). Concurrent training with different aerobic exercises. Int J Sports Med., 33(8), 627-34.

Santos, A. D., Nicolielo, M. A. M., \& Oliveira, M. R. (2016). Os Efeitos de treinamento funcional em praticantes de Ballet Clássico. p.64.

Scinocca, A. P. (2019). Ballet Pilates: tonifica e faz bem. https://emais.estadao.com.br/blogs/vigilante-da-causa-magra/pilates-tonifica-e-faz-bem/ Acesso em: 27/03/2019.

Zabka, F. F., Valente, H. G., \& Pacheco, A. M. (2011). Avaliação Isocinética dos Músculos Extensores e Flexores de Joelho em Jogadores de Futebol Profissional. Rev Bras Med Esporte, 17(3).

Zapparoli, F. Y., \& Riberto, M. (2017). Isokinetic Evaluation of the Hip Flexor and Extensor Muscles: A Systematic Review. Ribeirão Preto Medical School, São Paulo, Ribeirão Preto, Brasil. Revista de Esporte. 